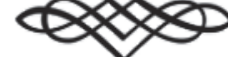

Fear seen from Law

\title{
El Miedo desde el Derecho
}

\section{Luis Bueno Ochoa}

Facultad de Derecho-ICADE

Universidad Pontificia Comillas de Madrid

lbueno@icade.comillas.edu

DOI: https://doi.org/10.15366/bp2021.27.016

Bajo Palabra. II Época. No 27. Pgs: 307-322

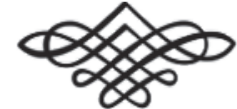


Recibido: 14/05/2020

Aprobado: 07/05/2021

Resumen

El miedo es considerada una emoción negativa que se asocia, comúnmente, con una visión catastrofista. Sin embargo, el mundo del Derecho propicia referirse a la equivocidad del miedo. El miedo y la esperanza se ven reconciliados, finalmente, tanto a partir de La dificultad de ser como en consideración a El coraje de ser.

Palabras clave: Miedo, Derecho, Esperanza, Dificultad de ser, Coraje.

\section{Abstract}

Fear is considered a negative emotion that is commonly associated with a catastrophic vision. However, the world of law favors refering such as an equivocal fear. At last, fear and hope are reconciled both from La Difficulté d'être and from The Courage to Be.

Keywords: Fear, Law, Hope, Difficulty of being, Courage. 
El auténtico problema es que una mayoría no quiere la libertad y aún le tiene miedo. Para llegar a ser libre

hay que ser libre, pues la libertad es existencia, concordancia consciente con la existencia, y es el placer, sentido como destino, de hacerla realidad ${ }^{1}$

\section{Prolegómenos}

Comenzar la exposición con una cita de Jünger que incide en la libertad y que, más bien de pasada, se refiere al miedo, puede no ser una manera adecuada de hacer los preparativos para aproximarnos a una emoción tan inquietante como es el miedo. Sin embargo, la cita de una obra tan emocionante como La Emboscadura (1951) sí justifica adentrarnos en un terreno tan enigmático, inconscientemente enigmático, cabría resaltar, como es el de las emociones y, singularmente, como el miedo.

La literatura psicológica, con cita de Paul Ekman, por ejemplo, suele distinguir entre seis emociones básicas: tristeza, felicidad, sorpresa, asco, miedo e ira ${ }^{2}$. También es clásica, valdría decir, la clasificación según la cual se distingue entre emociones positivas, negativas y ambiguas. El miedo, ni que decir tiene, se adscribe a la categoría de las emociones negativas, distinguiéndose, a su vez, de acuerdo con Karl Albrecht, cinco miedos básicos: miedo a la muerte, pérdida de autonomía, soledad, miedo a la mutilación y daños y perjuicios al ego ${ }^{3}$.

\footnotetext{
* Una versión inicial del presente trabajo, descargada de citas, dio lugar a la Comunicación presentada en fecha 05-02-2020 con ocasión de la celebración de las XXIV Jornadas Internacionales de Filosofía tituladas Pensar el Miedo, ¿nos da miedo el miedo mismo?, organizadas por la Facultad de Ciencias Humanas y Sociales de la Universidad Pontificia Comillas de Madrid.

1 Jünger, Ernst: La emboscadura, trad. de Andrés Sánchez Pascual, Barcelona, Tusquets, 1988.

2 Vid. Ekman, Paul: El rostro de las emociones: signos que revelan significado más allá de las palabras, trad. de Jordi Serra Aranda, Barcelona, Club Círculo de Lectores, 2013. Sobre el mundo de las emociones la película Inside Out (2015) constituye, pienso, una referencia que no conviene soslayar. El tándem Pixar-Disney trató de reconciliarnos con cinco, no seis, emociones básicas aprovechando la conjunción entre el estado de ánimo y los colores: alegría (amarillo), tristeza (azul), temor/miedo (morado), furia/ira (rojo) y desagrado/asco (verde).

3 Vid. Albrecht, Karl: «The (Only) 5 Fears We All Share», en Psycology Today, 22-03-2012, recuperado de https:// www.psychologytoday.com/intl/blog/brainsnacks/201203/the-only-5-fears-we-all-share. En resumen, los cinco miedos responden a lo siguiente: «1. Miedo a la muerte. El miedo a ser aniquilados y dejar de existir, más co-
} 
El miedo tiene, a la vista de lo expuesto en los dos párrafos iniciales que preceden, muy mala prensa. Se podría añadir una lista, casi sin fin, de referencias negativas. Desde citas archiconocidas hasta obras literarias o musicales, entre otras muchas, para corroborar esta visión estigmatizadora, si no demonizada, del miedo y sus allegados. No estará de más hacer hincapié en algún recorrido con el que dar cuenta de una imposible "visión de conjunto" y, a tal efecto, nos referiremos muy concisamente tanto a los allegados como a una breve muestra de citas y referencias literarias y, si acaso, musicales.

Entre los allegados al miedo habría que aludir a la ansiedad y la angustia; que es tanto como incidir en dos contextos como son el de la psicología y la filosofía, respectivamente. El miedo y la ansiedad difieren, en términos psicológicos, porque el primero, a diferencia de la segunda, sí tiene objeto. El miedo y la angustia, por su parte, nos llevan de vuelta al tema de la libertad a que se ha aludido en la cita del frontispicio dado que, en la filosofía de Kierkegaard, por ejemplo, «la angustia es el vértigo de la libertad»"; por más que el binomio miedo y angustia sea, y siga siendo, un tema particularmente relevante que podría llevarnos, con Freud, a distinguir entre la angustia real - «algo muy racional y comprensible, pudiendo ser definida como una reacción a la percepción de un peligro exterior, esto es, de un daño esperado y previsto" 5 - y la angustia neurótica-que, por enigmática e inadecuada, está asociada a las diversas fobias ${ }^{6}-$; y con Heiddeger, a identificar el miedo con lo "que

múnmente conocido como miedo a la muerte, proviene de una sensación primaria de todos los seres humanos por la supervivencia [...] 2. Pérdida de autonomía. El miedo a ser inmovilizados, paralizados, restringidos, sometidos, atrapados, encarcelados o controlados por circunstancias que están fuera de nuestro control. El temor a la libertad de nuestros movimientos naturales es común a casi todos nosotros [...] 3. La soledad. Totalmente contrapuesto al anterior, este miedo se relaciona con el pánico al abandono, al rechazo o a sentirnos despreciados. La pérdida de conexión con el mundo genera sensaciones de angustia ante la posibilidad de convertirnos en una persona no querida a la que nadie respete ni valore [...] 4. Miedo a la mutilación. Se trata del temor de perder cualquier parte de nuestra estructura corporal, la idea de tener límites en la movilidad de nuestro cuerpo o de perder la integridad de cualquier órgano, parte del cuerpo, o la función natural [...]. 5. Daños y perjuicios al ego. El miedo a sentirnos humillados, pasar vergüenza o cualquier otra situación de profunda desaprobación que amenace la pérdida de la integridad del ser (también conocida como muerte del ego)».

4 Vid. Kierkegaard, Søren: El concepto de angustia, trad. de Demetrio Gutiérrez Rivero, Madrid, Alianza, 2007. También la doble apelación al temor y temblor tomada de la frase paulina (que aparece en Filipenses, 2:12 y Efesios, 6:5 en relación con la obediencia del creyente, y en 1 Corintios, 2:3 para describir la propia actitud de Pablo en la predicación del Evangelio) podría contribuir a arreciar ese otro conflicto que se sustancia entre la fe y la conciencia. Vid., a este respecto, Kierkegaard, Søren: Temor y temblor, estudio introductorio por Darío González, Madrid, Gredos, 2010.

5 Freud, Sigmund: Lecciones introductorias al psicoanálisis, en Obras Completas, Tomo III, trad. de Luis López-Ballesteros y de Torres, Barcelona, RBA-Biblioteca Nueva, 2006, Lección XXV, La angustia, p. 2367. Esta angustia real que bien podríamos asimilar al miedo es considerada «una manifestación de los instintos de conservación del yo» (p. 2379).

6 Ibidem, pp. 2370-71. Sin perjuicio de lo expuesto, no está de más indicar que el tema de la angustia fue profusamente tratado por Freud antes y después de las Lecciones introductorias al psicoanálisis (1915-17 [1916-17], vols. XV y XVI); así, por ejemplo, con cita de los títulos de las obras según la Standard Edition traducida al castellano por José Luis Etcheverry para la bonaerense Amarrortu editores, S. A., tenemos, antes, Sobre la justificación de 
se sitúa en el interior de la naturaleza humana [...que] no es algo eliminable sino latente, dormitante pero constante» mientras que la angustia «es el estado de ánimo, el sentimiento, el escenario donde aparece, se da a ver como fenómeno, la nada».

Las citas en torno al miedo son, prácticamente, inacabables y de muy diverso alcance. La de Franklin Roosevelt -«a lo único que debemos temer es al miedo mismo" ${ }^{7}$ - bien pudiera complementarse con esa otra perteneciente a un personaje que ha pasado a engrosar, últimamente, la lista de apestados (¿innombrables?) como es Woody Allen, quien no tuvo empacho en admitir, con su ironía habitual, que «el miedo es mi compañero más fiel, jamás me ha engañado para irse con otro» ${ }^{8}$. También el miedo y, más específicamente, la cobardía, ha generado réditos utilitaristas conducentes a cuestionar toda una trayectoria. Así, un ejemplo paradigmático de lo residenciado en las antípodas del género hagiográfico lo encontramos en la «biografía no autorizada» -desmitificadora o, si se prefiere, escandalosa, hostil o adversa- con que Gil Bera subtituló su documentada diatriba contra Pío Baroja9.

Los tres títulos de las obras seleccionadas que evocan al miedo podrían ser los siguientes: El miedo a la libertad (1941), de Erich Fromm, una obra en la que se ve triangulada la secuencia miedo-angustia-libertad comienza refiriéndose en los dos primeros capítulos tanto a «la libertad como problema psicológico» como a «la ambigüedad de la libertad» ${ }^{10}$; Miedo a volar (1973), de Erica Jong, una novela de culto en

separar de la neurastenia un determinado sindrome en calidad de "neurosis de angustia" (1895[1894], vol III); A propósito de las críticas a la "neurosis de angustia" (1895, vol. III); Tres ensayos de teoría sexual (1905, vol. VII) y Análisis de la fobia de un niño de cinco años (1909, vol X); y, después, Inbibición, síntoma y angustia (1926 [1925] vol XX) y Nuevas conferencias de introducción al psicoanálisis: la angustia y la vida pulsional (1933 [1932], vol. XXII). Deviene oportuno, asimismo, traer a colación uno de los famosos seminarios del autor que protagonizara el llamado «retorno a Freud». Vid. Lacan, Jacques: Seminario 10 -La Angustia, 1962-63-, texto establecido por Jacques-Alain Miller, editor asociado Juan Granica, trad. de Enric Berenguer, Buenos Aires, Paidós, 2007.

7 The only thing we have to fear is fear itsel fue la famosa pronunciada por el 320 Presidente estadounidense en su discurso de toma de posesión, en plena Gran Depresión, el sábado 4 de marzo de 1933. Fue en el segundo párrafo del discurso en el que se insertó la célebre cita de referencia: «Esta gran nación resistirá como lo ha hecho hasta ahora, resurgirá y prosperará. Por tanto, ante todo, permítanme asegurarles mi firme convicción de que a lo único que debemos temer es al temor mismo, a un terror indescriptible, sin causa ni justificación, que paralice los arrestos necesarios para convertir el retroceso en progreso». Matus, Mauricio, Rodríguez Paula y Rubio, Juan Antonio: Discursos de la Historia Económica. De Roosevelt a Obama; declaración de intenciones, Sevilla, Asociación Española de Historia Económica-Universidad Pablo de Olavide, enero-junio de 2019, pp. 10-11, recuperado de https:/www.aehe.es/wp-content/uploads/2019/04/PHE-AEHE-48-2019-DISCURSOS-PRESIDENTES-USA-completo.pdf.

8 Vid., en orden a justificar la evocación de un personaje sin igual, Grueso, Natalio: Woody Allen. El último genio, Barcelona, Plaza y Janés, 2015.

9 Vid, GIL BERA, EDUARDO: Baroja o el miedo. Biografía no autorizada, Barcelona, Eds. Península, 2001. Dos expresivas citas se incluyen justo antes del Preámbulo: una, atribuida a Josep Pla - «Algún día se tendrá que decir la verdad sobre Barojan- y, otra, que reproduce unos versos del propio Baroja -Es el miedo./ El que prende está pálido y desencajado, y el que ha sido preso también./ Es el miedo./ El mundo tiembla de miedo y las músicas tocan himnos de victoria./ Es el miedo- (p. 9).

${ }^{10}$ Vid. Fromm, Erich: El miedo a la libertad, prefacio y trad. de Gino Germani, Barcelona, Paidós, 2004, pp. 25 y 43 y ss. 
la que convergen erotismo y feminismo, algo que, trasladado a nuestra época, tendría todas las trazas de quedar lastrado por ese canon biempensante con querencia militante, más que reflexiva, y en la que se puede leer, testimonialmente, puesto en boca de Isadora Wing, la protagonista, lo que sigue: «He aceptado el miedo como parte de la vida, específicamente el miedo al cambio... He seguido adelante a pesar de los latidos en el corazón que dicen: vuelve atrás.... ${ }^{11}$; y Frente al miedo (2015), una antología de textos de Antonio Escohotado cuya edición corrió a cargo de Guillermo Herranz y en la que se incluye, nada más empezar, el precitado extracto correspondiente a la famosa obra de Jünger. Es de interés, por su elocuencia, dejar constancia de los cuatro apartados en que se divide la obra del autor antologado: "pensar sin miedo», «miedo a uno mismo», «miedo a los demás» y, en cuarto y último lugar, «miedo al mundo», con lo que se describe ese poder de convocatoria-reacción y creatividad, siquiera sea «a la contra» (como la contracultura-Counterculture-, por ejemplo), que se aprecia en esta emoción que, lejos de paralizar, al menos en este caso, ha servido para motorizar todo un cuarteto de reacciones en forma de contribuciones que dotan de contenido a la antología de que se trata ${ }^{12}$.

Una última alusión a la música podría llevarnos por muy variados derroteros en los que no nos vamos a detener ${ }^{13}$ pudiendo conformarnos con las muestras mencionadas que ya han cumplido con la función de probar el carácter fatalista del miedo. Y es que, llegados a este punto, de lo que se trata es de introducir un cambio de rumbo, un progresivo cambio de rumbo, porque no todo es negativo, no todo es desfavorable cuando contemporizamos con el miedo. Precisamente las relaciones del miedo con el mundo del Derecho nos van a ofrecer la posibilidad de apreciar otra gama de matices que contrastarán, como veremos, con ese pronóstico de inobjetable negatividad que embadurna todo cuanto tenga que ver con el miedo. Así pues, demos entrada al miedo, aunque sea tímidamente, en el orbe del Derecho; y aun cuando se trate de una entrada señaladamente incompleta, sí asistiremos, eso es lo que se pretende, a un recreador elemento de contraste en comparación con la visión catastrofista afín al miedo.

\footnotetext{
${ }^{11}$ Jong, Erica.: Miedo a volar, trad. de Marta Pessarrodona, Barcelona, Noguer Ed., 1978.

12 Escohotado, Antonio: Frente al miedo, edición de Guillermo Herranz, Barcelona, Página Indómita, 2015.

13 Con todo, no me resisto a compartir un par de referencias que resuenan, que siguen resonando: por un lado, el espectáculo multimedia en 3D -teatro musical- así titulado, Miedo, del polémico Albert Pla, cuya gira dio comienzo en 2018 y en cuya presentación se hace constar que «el texto propone un viaje íntimo por todas las etapas del hombre desde la infancia hasta más allá de la vida terrena cargado de sensaciones, emociones y sentimientos nacidos del fantasma que habita en nuestra mente, alimentado por nuestros pensamientos: el miedo». Vid. Pla, Albert \& Refree, Raül: Miedo (CD), Ridarenes (Girona), Enunplisplasmúsica, 2018; y, por otro, el tema "El miedo que tengo" incluido en el álbum Tú no existes (CD), Barcelona, Sinnamon Records, 2007, del grupo Astrud en el que las repeticiones - $\mathrm{El}$ miedo que tengo» y «¿Cómo no tenerlo?»- contrastan, deliciosamente, con sendos temas anteriores como "No tengo miedo al futuro», en Algo cambió (CD), Barcelona, Sinnamon Records, 2006, y «No tengo miedo», en Todos nos parece una mierda (EP), Barcelona, Sinnamon Records, 2004 y en Un Mystique Determinado (CD), Barcelona, Austrohúngaro, 2003.
} 
No obstante lo anterior, la actualidad obliga a que dicho ejercicio de recreación no pueda abstenerse de contextualizar con lo que la acción del miedo está dando de sí. Dos muestras bastarán para llevar a buen fin este propósito. Por un lado, corresponde dirigir la mirada cinco años atrás para fijarnos en la profética y no atendida intervención de Bill Gates acerca del ébola en la que concluía que «tenemos que actuar ya, porque el tiempo corre. En realidad, si hay algo positivo que puede derivarse de la epidemia de ébola es que pudo servir de alarma temprana, de despertador, para que nos alistemos. Si empezamos ahora, tal vez estaremos listos para la próxima epidemia» ${ }^{14}$. Y por otro, el mediático Byung-Chul Han acaba de reformular la tensión entre libertad y seguridad al contraponer las acciones del Estado policial digital al estilo chino frente a la forma que tiene Occidente de encarar la pandemia del Coronavirus (COVID-19), que ha redoblado el miedo hasta hablar de pánico: pánico porque se han vuelto a «erigir umbrales inmunológicos y a cerrar fronteras» $y$, de nuevo, pánico "que tiene que ver con la digitalización [en vista de que] la digitalización elimina la realidad» ${ }^{15}$.

\section{El miedo en nuestro Derecho}

Puestos A SEÑALAR UN PAR DE NOTAS introductorias acerca de la histórica relación del Derecho y el miedo habríamos de remontarnos hasta el Derecho Romano y las Siete Partidas. Así, cabe citar, por una parte, la actio quod metus causa, una acción pretoria introducida a finales del siglo II A. C. que, fundada en el miedo - metus-o violencia -vis-, podía ejercitar aquel que intervino en un negocio jurídico facultándole, en su caso, para solicitar la condena al cuádruplo del valor del daño causado ${ }^{16}$; y, por otra, Las Siete Partidas, en las que se estableció la invalidez de los litigios y/o de las declaraciones realizadas bajo miedo al prever que .... Otrosi decimos que "metus" en latin tanto quiere decir en romance como miedo de muerte, ó de tormento del cuerpo, ó de perder libertad, ó las cartas por que la podrie amparar, ó recebir deshonra por que fincarie enfamado: et de tal miedo como este ó de otro semejante fablan las leyes deste nuestro libro quando dicen que pleyto ó postura que home faga por miedo, que

${ }^{14}$ Gates, Bill: «¿La próxima epidemia? No estamos listos» (The next outbreak? Wére not ready), trad. de Francisco Gnecco y revisión de Ciro Gómez, TED Conference, Vancouver, marzo 2015, recuperado de https://www.ted. com/talks/bill_gates_the_next_outbreak_we_re_not_ready/transcript?language=es.

15 Han, Byung-Chul: «La emergencia viral y el mundo de mañana», trad. de Alberto Ciria, Diario El País, 22-032020, recuperado de https://elpais.com/ideas/2020-03-21/la-emergencia-viral-y-el-mundo-de-manana-byungchul-han-el-filosofo-surcoreano-que-piensa-desde-berlin.html.

16 Vid. un estudio detallado de la acción referenciada en Calore, Emanuela: "Actio quod metus causa". Tutela della vittima e azione in rem scripta, Milano, Giuffré, 2011. 
non debe valer... ${ }^{17}$. No obstante lo anterior, lo que se pretende ahora es reorientar la exposición para hacer ver que adentrarnos en el mundo del Derecho equivale a rehuir el catastrofismo. Es preciso aclarar, así las cosas, que aludiremos a nuestro Derecho y, más concretamente, a las líneas generales de la regulación en materia civil y penal y poco más.

En Derecho Civil sustantivo (léase el Código Civil -Cc-) el miedo aparece por partida doble en materia de contratación. Refirámonos, pues, a la intimidación - Hay intimidación cuando se inspira a uno de los contratantes el temor racional y fundado de sufrir un mal inminente y grave en su persona o bienes, o en la persona o bienes de su cónyuge, descendientes o ascendientes- (art. 1.267 párrafo 2ª, Cc- así como al temor reverencial-El temor de desagradar a las personas a quienes se debe sumisión y respeto no anulará el contrato-, art. 1.267 , párrafo $\left.4{ }^{\circ}, \mathrm{Cc}\right)$.

Como es de ver únicamente la variante de la intimidación, y no la del temor reverencial, constituye un supuesto de anulabilidad contractual. Así pues, el mero temor reverencial (metus reventialis) no es susceptible de anulabilidad si no alcanza la cualidad de miedo intimidatorio. La intimidación se refiere, pues, al cariz amenazante del miedo (por su entidad e incidencia -según edad y condición- y otra serie de requisitos sentados por la jurisprudencia) de manera que la gradación del miedo depara consecuencias particularmente diferentes hasta el punto de considerar que en un caso, y no en el otro, queda comprometida la prestación del consentimiento en tanto en cuanto elemento esencial del contrato (art. $1.261 \mathrm{Cc}$ ). Así pues, también para el Derecho hay miedos y miedos. Nótese que por vez primera aparece el miedo en plural. La pluralidad del miedo, los miedos, contribuyen, como tendremos ocasión de comprobar, a ir despejando el terreno.

En Derecho Penal sustantivo (léase, el Código Penal-CP-), el que obre impulsado por miedo insuperable quedará exento de responsabilidad penal (art. 20.6 ${ }^{\circ} \mathrm{CP}$ ). El miedo insuperable, por más que pueda considerarse una modalidad -o especialidaddel estado de necesidad (art. 20.5 $\mathrm{CP}$ ) constituye una circunstancia eximente a la que se reconoce autonomía. El carácter insuperable del miedo hace alusión a una esencial naturaleza subjetiva que se refiere al miedo normalmente padecido por el hombre medio o la generalidad de las personas ante una situación o causa hábil para producirlo.

Con el par de pinceladas que anteceden hemos podido comprobar que el miedo tiene diferentes caras. La univocidad del miedo queda, pues, en entredicho. Y es

\footnotetext{
${ }_{17}$ Las Siete Partidas del Rey Don Alfonso El Sabio, cotejadas con varios códices antiguos por la Real Academia de Historia, Madrid, Imprenta Real, 1807, Setena Partida -Deste libro, que fabla de todas las acusaciones et malfetrias que los homes facen por que merescen haber pena-, Título XXXIII -Del significamiento de las palabras et de las cosas dubdosas et de las reglas derechas-, Ley VIII -De la interpretación de otras palabras dubdosas-, Tomo III, p. 721, recuperado de http://fama2.us.es/fde/lasSietePartidasEd1807T3.pdf.
} 
que el miedo puede permitir, según lo expuesto, tanto anular un contrato como evitar ser penalmente responsable. La equivocidad del miedo es, precisamente, la que abre paso a una visión que cuestiona el encasillamiento del miedo ante un panorama de objetable negatividad.

Como muestras adicionales de la equivocidad del miedo podemos recurrir a tres supuestos más. Uno, tiene que ver con el Derecho adjetivo; y los otros dos guardan relación con el Derecho Administrativo y el Derecho del Trabajo, respectivamente, con miras a ampliar, mínimamente, el alcance de esta rápida visión panorámica.

En el Derecho adjetivo supletorio (léase la Ley de Enjuiciamiento Civil-LEC- a tenor de lo preceptuado en su art. 4), el miedo y, más concretamente, la temeridad, se mantiene como criterio de adopción de aplicación subsidiaria, más allá del principio objetivo del vencimiento, en materia de imposición de costas (art. 394.2 LEC y concordantes). La temeridad de la que hace gala el litigante temerario, valga la redundancia, puede no resultar, por tanto, inocua. Dicha temeridad, o sea, el desprecio del miedo por parte de quien actúa de manera «excesivamente imprudente arrostrando peligros» (a tenor de lo recogido en la primera de las acepciones de la voz temerario en el DRAE) cumple una función penalizadora. El miedo, por consiguiente, tiene que ser modulado dado que ningunear al miedo, pasarlo por alto, no sale $-\mathrm{o}$ puede no salir- gratis.

El miedo no resiste, por cuanto antecede, el singular y nos lleva hasta el miedo plural. Nos dirige, por ejemplo, a otros miedos -llamémosles jurídicos- como «el miedo o terribilita en la gerencia» o el miedo al trabajo o al despido ${ }^{18}$.

La terribilità expresada, que no oculta, por cierto, evidentes resonancias artísti$\operatorname{cas}^{19}$, propicia esculpir un miedo próximo al castigo que se desenvuelve, conectado con la desobediencia, en un entorno conocido como el denominado NPG (New Public Management). Otro ejemplo más de las inacabables, si no inesperadas, ramificaciones del conjunto de miedos manifiestos y, sobre todo, latentes.

Entre los miedos que también tienen proyección en el Derecho se encuentra el miedo -patológico- al trabajo (ergofobia) que, ciertamente, está íntimamente relacionado con el miedo al despido ${ }^{20}$.

\footnotetext{
${ }^{18}$ Lorenzo de Membiela, Juan B.: «El miedo o “terribilita” en la gerencia», en Revista Aragonesa de Administración Pública, 2010, núm. 37, pp. 225-238.

19 Terribilità es una expresión italiana asociada al Cinquecento y, en particular, al estilo grandioso y de poderosa fuerza espiritual, temperamental y exaltado, que adoptara la obra del afamado Michelangelo Buonarroti en esculturas tales como David (1501-04) o Moisés (1513-15). Más modernamente dicho término ha sido puesto en relación, desde el prisma del psicoanálisis, con el par locura-creatividad. Vid. Gedo, John E.: Portrais of the artist. Psychoanalysis of Creativity and Its Vicissitudes, introd. by Peter Gay, Chapter 9 ("Terribilità: The Paranoid Monster as Creative Genius»), Hillsdale (New Jersey), The Analityc Press, 1989.

${ }^{20}$ La ergofobia o miedo al trabajo y, por extensión, el miedo al despido, se asocia, a su vez, con el síndrome de burnout que está tan en boga en los últimos tiempos. Vid. Camacho Quintero, Carlos L.: «Una mirada desde el Sín-
} 
Con los dos miedos anteriores, que no son sino manifestaciones de la incertidumbre, la precariedad y la vulnerabilidad inherente a la condición humana, cerramos el círculo de miedos que han preparado el terreno para acometer un verdadero cambio de rumbo que se plasmará en el apartado siguiente.

Hasta ahora, digámoslo a modo de parcial recapitulación, la intimidación, el temor reverencial, el miedo insuperable y la temeridad (sin descontar las referencias finales al miedo -o terribilita- en la gerencia y la ergofobia) han mostrado una amplia y diversa gradación del miedo cuyas particulares consecuencias hemos dado en adscribir a la equivocidad del miedo. Pues bien, esta equivocidad en que se instala tamaña pluralidad es la que va a hacer posible romper una lanza, o más de una, a favor del miedo.

\section{Con miedo y esperanza}

Aludir a una CONCEPCIÓn DEL MIEDo que preste acogida a sus efectos benéficos (o, si se prefiere, salutíferos) nos lleva hasta Thomas Hobbes. Ya en su autobiografía hizo ver, sin incurrir en jeremiadas, que el miedo había sido para él como un hermano gemelo ${ }^{21}$. El sentimiento del miedo, sostenía, llamaba a la asociación en detrimento de la dominación puesto que, efectivamente, «nadie debe dudar de que los hombres por su naturaleza, si no existiese el miedo, se verían inclinados más al dominio que a la sociedad. Por lo tanto hay que afirmar que el origen de las sociedades grandes y duraderas no se ha debido a la mutua benevolencia de los hombres sino al miedo mutuo» ${ }^{22}$.

La toma de posición precedente aún nos permite dirigir la mirada todavía más atrás aunque sea a costa de retorcer el argumento. Recordemos, así, que Nec spe, nec metu fue el lema que hicieron suyo, imbuidos de estoicismo, los valerosos gladiadores romanos que más tarde fue atribuido a Isabella d'Este, Marquesa de Mantua, la primadonna del Renacimiento, si bien su origen está más relacionado, al parecer, con la obra de Cicerón ${ }^{23}$. Esta negación del miedo y, por extensión, de la esperanza, acorta tanto el recorrido que, siquiera sea desde el prisma del más elemental principio de

drome de Burnout hacia la Gerencia Integral en el Siglo XXI», en Revista Scientific (Instituto Internacional de Investigación y Desarrollo Tecnológico Educativo INDTEC, C. A.), vol. 4, núm. 13, agosto-octubre de 2019, pp. 40-59, recuperado de http://www.indteca.com/ojs/index.php/Revista_Scientific/article/view/345/483.

${ }^{21}$ Vid. Hobbes, Thomas: Diálogo entre un filósofo y un jurista y escritos autobiográficos, trad. de Miguel Ángel Rodilla González, Madrid, Tecnos, 1992.

${ }^{22}$ Hobbes, Thomas: El Ciudadano, edición (introducción, traducción y notas) de Joaquín Rodríguez Feo, Madrid, CSIC-Editorial Debate, 1993, I, 2, p. 17.

23 Vid. Gómez de Liańo, Javier: «Sin esperanza ni miedo», en El Español, 11-02-2019, recuperado de https://www. elespanol.com/opinion/tribunas/20190211/sin-esperanza-miedo/375332466_12.html. Según el autor y, más 
autodefensa (léase al modo darwinista, si se prefiere, como instinto de conservación y perpetuación), se impone invertir el lema y abonarse al miedo esperanzado o, dicho de otra manera, a la esperanza; aunque sea con ribetes de viviente pusilanimidad.

Si el precio del horizonte vital pasa por sentir y contemporizar con el miedo, así será; será con miedo y será, también será, seguirá siendo, con esperanza. El comúnmente denominado pesimismo hobbessiano, en contraste con el optimismo rousseauniano y, si acaso, kantiano, hace posible continuar por más que el anterior haz de divergencia -optimista-pesimista- no consiga desasirse del prejuicio de los lugares comunes a los que tanta punta sacó el genio de Flaubert ${ }^{24}$.

Corresponde, pues, plantearse, apelando a las vías de hecho, continuar (la expresión to be continued deja bien a las claras que se trata de continuar para ser, para seguir siendo). $Y$ es que seguir es resistir, o sea, no cejar en el empeño. La prudencia y la templanza son, en este sentido, las virtudes -cardinales- que acompañan al miedo: un doble ejercicio de prudencia y templanza que se propone, sin descuidar la fortaleza que resulta de la dosificación, que las emociones no puedan negarse; tampoco aquellas enraizadas en el sentimiento del miedo. Se trata, pues, de convivir con ese alud de miedos para ser y, aunque suene a pleonasmo, para seguir siendo. Es difícil no caer en la tentación de poner como ejemplo el de los toreros (sin ánimo de molestar y, al tiempo, sin complejos para no abstenernos de decir) en quienes los miedos se logran modular con las suficientes dosis de prudencia, fortaleza y templanza (no se hace mención a la virtud cardinal que el lector echará en falta porque la justicia, llamémosla ahora torera, «se le supone», de la misma manera que vimos cumplimentado, don dos eses mayúsculas, el apartado «valor» de la Cartilla del Servicio Militar). Sobre todo con templanza, subrayémoslo, porque la receta de «parar, templar y mandar» es la indicada para enfrentar, dominar y transformar los miedos que han de culminar en la suerte-muerte final.

Los miedos y el ser, para seguir siendo, están condenados, por tanto, a convivir. Porque convivir con ese miedo que se dispara en tantos y tan diferentes miedos des-

en concreto, según le contaron unos jueces londinenses, el lema Nec spe nec metu «es la fórmula de juramento preferida por la judicatura inglesa».

24 Dejemos constancia de que en el peculiar diccionario al que nos referimos la voz «miedo" (peur) va seguida de la frase «pone alas en los pies» (donne des ailes). Vid. Flaubert, Gustave: Diccionario de lugares comunes, Aviso al lector de Alberto Ciria, Espacio disponible, editado por elaleph.com, 1999, recuperado de http://190.186.233.212/ filebiblioteca/Literatura\%20General/Gustavo\%20Flaubert\%20-, y, asimismo, Dictionnaire des idées reçues, (Euvre posthume publication en 1913), Edition du groupe «Ebooks libres et gratuits», 4 de julio de 2003, recuperado de https://www.ebooksgratuits.com/pdf/flaubert_dictionnaire_des_idees_recues.pdf. La anterior referencia puede verse complementada con esta otra, según la cual, el miedo es la «sensación de verse privado de futuro inmediato" a la que acompańan unos versos atribuidos al Conde de Montrose: Quien tiene demasiado miedo a su destinol o sus bazas son muy bajas, / no se atreve a ponerlo a pruebal y preferiría pasar antes que enseñar las cartas. Bierce, Ambrose: El diccionario del diablo, edición de Ernest Jerome Hopkins, trad. y notas de Vicente Campos, Barcelona, Debolsillo (Random House Mondadori), 2007, pp. 326-327. 
emboca en una tarea, la de ser, que es, posiblemente, la tarea vital por antonomasia. Tarea difícil que requiere coraje y en cuyo itinerario podríamos trazar dos polos que más bien conforman, incesantemente y en constate renovación, un continuum: el de «la dificultad de ser» (La Diffculté d'etre) y el de «el coraje de ser» (The Courage to $\mathrm{Be}$ ).

En el epílogo de La dificultad de ser (1998) Jean Cocteau mantenía un diálogo consigo mismo -en el que repetidamente se llamaba «intrépido y estúpido»- y en el que la dificultad -o el miedo- de ser aún dejaba un hálito esperanza:

«Hete aquí curado, intrépido. Intrépido y estúpido, zarandeado en este desorden que aborreces, siempre huyendo de algo, en camino hacia algo, con el trineo rodeado de nieves de lobos" ${ }^{25}$.

Curado y solo, seguía diciendo, terminaba con una corajuda exclamación:

«iPues apánatelas, intrépido! Intrépido y estúpido, adelante. Atrévete a ir hasta el final» ${ }^{26}$.

También en el último pasaje de El coraje de ser (1952) de Paul Tillich se apreciaba un mismo aire de familia al de los escritos póstumos de Cocteau. Aunque no hubiera ya ningún poder especial capaz de vencer la culpa, el coraje del ser seguía haciendo acto de presencia:

«El coraje de tomar la angustia del absurdo sobre sí mismo es la línea fronteriza a donde puede llegar el coraje. Más allá está la nada. Dentro de ella pueden ser restablecidas todas la formas de coraje en el poder del Dios por encima del Dios del deísmo. El coraje de ser está arraigado en el Dios que aparece cuando Dios $b \quad a$ desaparecido en la angustia de la duda» ${ }^{27}$.

Dificultad y coraje al abrigo del miedo ${ }^{28}$ y la esperanza, todo ello precipitado por unas cuantas alusiones provenientes del mundo del Derecho, esbozan el intrincado paraje en el que nos hemos visto rodeados con la aspiración de seguir siendo.

${ }_{25}$ Cocteau, Jean: La dificultad de ser, trad. de María Teresa Gallego Urrutia, Madrid, Siruela, 2006, Epílogo, p. 153.

26 Ibidem, p. 153.

${ }^{27}$ Tillich, Paul: El coraje de ser, prólogo de Diego Sánchez Meca y trad. de José Luis Lana, Madrid, Avarigani, 2018, VI.2.3. El Dios por encima de Dios, y el coraje de ser, p. 204.

${ }_{28} \mathrm{El}$ par miedo-coraje es, precisamente, al que aludió Mario Benedetti en un poema inédito, muy pertinente en este momento conclusivo, que dice así: El miedo y el corajel son gajes del oficio/pero si se descuidan/los derrota el olvido./ el miedo se detienel a un palmo del abismo/ y el coraje no sabel qué hacer con el peligro./ el miedo no se atreve (a atravesar el rio/ y el coraje rechazal el mar del infinito./ no obstante hay ocasiones/ que se abren de improviso/ y alli miedo y corajel son franjas de lo mismo. Benedetti, Mario: «Miedo y coraje», en Valero Juan, Ana: «La biblioteca madrileña de Benedetti", en Boletín del Centro de Estudios Iberoamericanos Mario Benedetti, núm. 1, enero-junio 2013, Alicante, Universitat d'Alacant, pp. 28-29, recuperado de https:/web.ua.es/es/centrobenedetti/documentos/boletin-cemab/boletin-cemab-n1.pdf. 


\section{REFERENCIAS BIBLIOGRÁFICAS}

ALBRECHT, KARL: «The (Only) 5 Fears We All Share», en Psycology Today, 22-03-2012, recuperado de https://www.psychologytoday.com/intl/blog/brainsnacks/201203/ the-only-5-fears-we-all-share.

ASTRUD: «El miedo que tengo», en Tú no existes (CD), Barcelona, Sinnamon Records, 2007.

.- «No tengo miedo al futuro», en Algo cambió (CD), Barcelona, Sinnamon Records, 2006.

.- «No tengo miedo», en Todos nos parece una mierda (EP), Barcelona, Sinnamon Records, 2004, y en Un Mystique Determinado (CD), Barcelona, Austrohúngaro, 2003.

BENEDETTI, MARIO: «Miedo y coraje», en Valero Juan, Ana: «La biblioteca madrileña de Benedetti», en Boletín del Centro de Estudios Iberoamericanos Mario Benedetti, núm. 1, enero-junio 2013, Alicante, Universitat d'Alacant, pp. 2829 , recuperado de https://web.ua.es/es/centrobenedetti/documentos/boletin-cemab/boletin-cemab-n1.pdf.

BIERCE, AMBROSE: El diccionario del diablo, edición de Ernest Jerome Hopkins, trad. y notas de Vicente Campos, Barcelona, DEBOLS!LLO (Random House Mondadori), 2007.

CALORE, EMANUELA: "Actio quod metus causa". Tutela della vittima e azione in rem scripta, Milano, Giuffré, 2011.

CAMACHO QUINTERO, CARLOS L.: «Una mirada desde el Síndrome de Burnout hacia la Gerencia Integral en el Siglo XXI», en Revista Scientific (Instituto Internacional de Investigación y Desarrollo Tecnológico Educativo INDTEC, C. A.), vol. 4, núm. 13, agosto-octubre de 2019, pp. 40-59, recuperado de http://www.indteca.com/ojs/index.php/Revista_Scientific/article/ view/345/483.

COCTEAU, JEAN: La dificultad de ser, trad. de María Teresa Gallego Urrutia, Madrid, Siruela, 2006.

EKMAN, PAUL: El rostro de las emociones: signos que revelan significado más allá de las palabras, trad. de Jordi Serra Aranda, Barcelona, Club Círculo de Lectores, 2013.

ESCOHOTADO, ANTONIO: Frente al miedo, edición de Guillermo Herranz, Barcelona, Página Indómita, 2015. 
FERRER GARCÍA, ALBERTO: «Temblor sin temor: miedo y angustia en la filosofía de Martin Heidegger», en Factótum, 10, 2013, pp. 61 y 67, recuperado de http://www.revistafactotum.com/revista /f_10/ articulos /Factotum_10_5_ Alberto_ Ferrer.pdf.

FLAUBERT, GUSTAVE: Diccionario de lugares comunes, Aviso al lector de Alberto Ciria, Espacio disponible, editado por elaleph.com, 1999, recuperado de http://190.186.233.212/filebiblioteca/Literatura\%20General/Gustavo\%20 Flaubert\%20-, y, asimismo, Dictionnaire des idées reçues, (Euvre posthume publication en 1913), Edition du groupe «Ebooks libres et gratuits», 4 de julio de 2003, recuperado de https://www.ebooksgratuits.com/pdf/flaubert_dictionnaire_des_idees_recues.pdf.

FREUD, SIGMUND: Lecciones introductorias al psicoanálisis, en Obras Completas, Tomo III, trad. de Luis López-Ballesteros y de Torres, Barcelona, RBA [Biblioteca Nueva], 2006, Lección XXV, La angustia, pp. 2367-2379.

FROMM, ERICH: El miedo a la libertad, prefacio y trad. de Gino Germani, Barcelona, Paidós, 2004.

GATES, BILL: «¿La próxima epidemia? No estamos listos» (The next outbreak? Wére not ready), trad. de Francisco Gnecco y revisión de Ciro Gómez, TED Conference, Vancouver, marzo de 2015, recuperado de https://www.ted.com/ talks/bill_gates_the_next_outbreak_we_re_not_ready/transcript?language=es.

GEDO, JOHN E.: Portrais of the artist. Psychoanalysis of Creativity and Its Vicissitudes, introd. by Peter Gay, Chapter 9 («Terribilità: The Paranoid Monster as Creative Genius»), Hillsdale (New Jersey), The Analityc Press, 1989.

GIL BERA, EDUARDO: Baroja o el miedo. Biografía no autorizada, Barcelona, Eds. Península, 2001.

GÓMEZ DE LIAÑO, JAVIER: «Sin esperanza ni miedo», en El Español, 11-022019, recuperado de https://www.elespanol.com/opinion/tribunas/20190211/ sin-esperanza-miedo/375332466_12.html.

GRUESO, NATALIO: Woody Allen. El último genio, Barcelona, Plaza y Janés, 2015.

HAN, BYUNG-CHUL: «La emergencia viral y el mundo de mañana», trad. de Alberto Ciria, Diario El País, 22-03-2020, recuperado de https://elpais.com/ ideas/2020-03-21/la-emergencia-viral-y-el-mundo-de-manana-byung-chulhan-el-filosofo-surcoreano-que-piensa-desde berlin.html.

HOBBES, THOMAS.: Diálogo entre un filósofo y un jurista y escritos autobiográficos, trad. de Miguel Ángel Rodilla González, Madrid, Tecnos, 1992. 
- - El Ciudadano, edición (introducción, traducción y notas) de Joaquín Rodríguez Feo, Madrid, CSIC-Editorial Debate, 1993.

JONG, ERICA.: Miedo a volar, trad. de Marta Pessarrodona, Barcelona, Noguer Ed., 1978.

JÜNGER, ERNST: La emboscadura, trad. de Andrés Sánchez Pascual, Barcelona, Tusquets, 1988.

KIERKEGAARD, SØREN.: El concepto de angustia, trad. de Demetrio Gutiérrez Rivero, Madrid, Alianza, 2007.

- - Temor y temblor, estudio introductorio por Darío González, Madrid, Gredos, 2010.

LACAN, JACQUES: Seminario 10 -La Angustia, 1962-63-, texto establecido por Jacques-Alain Miller, editor asociado Juan Granica, trad. de Enric Berenguer, Buenos Aires, Paidós, 2007.

LAS SIETE PARTIDAS DEL REY DON ALFONSO EL SABIO, cotejadas con varios códices antiguos por la Real Academia de Historia, Madrid, Imprenta Real, 1807, Tomo III, recuperado de http://fama2.us.es/fde/lasSietePartidasEd1807T3.pdf.

LORENZO DE MEMBIELA, JUAN B.: «El miedo o "terribilita" en la gerencia», en Revista Aragonesa de Administración Pública, 2010, núm. 37, pp. 225238.

MATUS, MAURICIO, RODRÍGUEZ PAULA Y RUBIO, JUAN ANTONIO: Discursos de la Historia Económica. De Roosevelt a Obama; declaración de intenciones, Sevilla, Asociación Española de Historia Económica-Universidad Pablo de Olavide, enero-junio de 2019, pp. 10-11, recuperado de https://www.aehe. es/wp-content/uploads/2019/04/PHE-AEHE-48-2019-DISCURSOS-PRESIDENTES-USA-completo.pdf.

PLA, ALBERT \& REFREE RAÜL: Miedo (CD), Ridarenes (Girona), Enunplisplasmúsica, 2018.

TILLICH, PAUL: El coraje de ser, prólogo de Diego Sánchez Meca y trad. de José Luis Lana, Madrid, Avarigani, 2018.

DOI: https://doi.org/10.15366/bp2021.27.016

Bajo Palabra. II Época. № 27. Pgs: 307-322 
